\title{
Endovascular Treatment of Intracranial Ophthalmic Segment Aneurysms: A Series and Literature Review
}

\author{
Rong-Bo QU' ${ }^{1}$, Hua JIN² \\ ${ }^{1}$ Yantai Affiliated Hospital, Department of Neurosurgery, Yantai, Shandong, China \\ ${ }^{2}$ The Third Affiliated Hospital of Harbin Medical University, Department of Neurosurgery, Harbin, Heilongjiang, China \\ The authors contributed equally to this research.
}

\section{ABSTRACT}

AIM: To present the outcomes and follow-up results of endovascular coil embolization in patients with ophthalmic segment aneurysms (OSAs).

MATERIAL and METHODS: The data of 42 patients with 44 OSAs (7 ruptured and 37 unruptured), who underwent treatment using endovascular techniques between January 2007 and November 2010, were retrospectively reviewed.

RESULTS: The angiographic occlusion of the aneurysms was complete for 37 aneurysms (84.1\%), near complete for 4 aneurysms $(9.1 \%)$ and incomplete occlusion for 3 aneurysms (6.8\%). There were $2(4.5 \%)$ symptomatic procedure-related complications (ischemic events). One patient died of massive cerebral infarction caused by a large dissecting OSA. A favorable outcome was achieved in $97.6 \%$ (41 of 42) of the patients at the time of follow-up. No sign of bleeding or re-bleeding was observed in any patient during the follow-up period (1 to 44 months, mean 14.2 months). Minor aneurysm recanalization occurred in 2 (4.5\%) cases. The OSA-associated visual disorders completely recovered in 9 (64.3\%) patients.

CONCLUSION: Endovascular treatment is a safe and effective treatment modality for intracranial OSAs.

KEYWORDS: Intracranial aneurysm, Ophthalmic segment, Carotid artery, Endovascular treatment

\section{INTRODUCTION}

Anatomical complexity of the paraclinoid region has made surgical treatment of intracranial ophthalmic segment aneurysm (OSA) difficult. The clinical outcome of patients is occasionally compromised by complications after clipping operations.

With advances in endovascular techniques, coiling of intracranial aneurysms became a valid and safe alternative to surgical treatment $(4,19)$. However, OSAs are usually considered be larger and more wide-necked than those located in other locations, pose particular technical challenges for endovascular treatment, and the anatomical complexity of the paraclinoid region makes surgical treatment challenging $(1,4,5,6,22,27)$ These challenges are related to the inability to obtain a stable microcatheter position, the necessity of stent assistance, as well as skull base techniques. For these reasons, there are few studies pertinent to OSA treatment. However, with improved endovascular devices, increasing endovascular embolization experiences, and the introduction and widespread adoption of the adjunctive technique of stentassisted coiling, OSA has been treated with endovascular techniques frequently in our center $(15,26)$.

We report our own experience in order to improve the understanding of safety and efficacy profiles associated with the endovascular treatment of OSAs. 


\section{- MATERIAL and METHODS}

Between January 2007 and November 2010, the data of 42 consecutive patients with 44 OSAs, who were treated with endovascular coil embolization at our institution, were retrospectively reviewed. Clinical and radiographic data of 42 patients were reviewed. There were 12 men (28.6\%) and 30 women $(71.4 \%)$ with a mean age of 50.8 years (range $15-78$ years).

Typically, a $5 \mathrm{~F}$ or $6 \mathrm{~F}$ guiding catheter was placed into the internal carotid arteries. All of the rotation digital subtraction angiography (DSA) examinations were performed by using a digital angiography suite (GE Medical Systems). A volume of $18 \mathrm{~mL}$ of non-ionic contrast medium was injected through a $5 \mathrm{~F}$ guiding catheter using an injector with a velocity of $3 \mathrm{~mL} / \mathrm{s}$. DSA images of the entire circulation were usually obtained, followed by a "working-projection" DSA. Patients were typically treated under general anesthesia (4). Heparin was administered intravenously just after the guiding catheter was introduced, first as a $3000-U$ bolus followed by infusions at $1000 \mathrm{U} /$ hour. A coaxial technique was used for microcatheter, balloon, and stent catheter access. In general, balloon assist was used in 2 cases and stent was used in 26 cases.

Outcomes for endovascular coiling were stratified into 3 categories based on the degree of angiographic aneurysm filling just after the coiling (4):

1. Complete or nearly complete occlusion: It is defined as a lack of angiographic filling of the aneurysmal sac and the neck, or no filling of the sac but small residual neck filling, respectively.

2. Incomplete occlusion: It is defined as persistent angiographic filling of a portion or portions of the aneurysmal sac.

3. Failed occlusion: It is defined as an aneurysm that could not be embolized. Thus, no coil was introduced or remained in the aneurysm.

The outcome of each procedure was determined by the operator, who evaluated the post-procedural 3D-DSA images of the aneurysm. Immediate post-procedural outcomes, as well as a 6-month angiographic follow-ups, were collected in this study.

Peri-procedural complications for each procedure were also recorded. Complications were determined by the operator who performed the endovascular embolization. Data on morbidity and mortality resulting from these complications were also recorded.

\section{Clinical and Angiographic Follow-Up}

The patient's clinical status was checked at the time of follow-up by using the Glasgow Outcome Scale (GOS) and conventional angiography was performed.

A GOS score of 5 means good recovery (normal daily life despite minor deficits), a GOS score of 4 means moderate disability (disabled but independent), a GOS score of 3 means severe disability (conscious, but disabled and dependent for daily life), a GOS score of 2 means a persistent vegetative state, (unresponsive to stimuli and no speech), and a GOS score of 1 means death of the patient $(9,12)$.

Major recanalization was defined as contrast filling within the aneurysm dome, or significant coil loosening or compaction. Minor aneurysm recanalization was defined as minimal coil compaction at the aneurysm neck $(10,12)$. If there was a neck remnant at the end of the embolization procedure and the neck remnant persisted at follow-up period without any increase, the radiographic condition was defined as "stable occlusion" rather than recanalization (12). The Fisher exact and Student's test were performed with software (SPSS version 16.0, SPSS Inc. Chicago, IL).

\section{RESULTS}

There were 7 (15.9\%) ruptured and 37 (84.1\%) unruptured OSAs (Table I). Among the patients with ruptured aneurysms, the Hunt and Hess grade was I in 5 patients, and III in 2. Among the patients with unruptured OSAs, 14 patients presented with visual disorders, including blurred vision $(n=7)$, cranial nerve III palsy $(n=4)$ and cranial nerve VI palsy $(n=3)$, associated with OSAs and the other 21 patients were incidental. Among the 44 aneurysms, 2 were dissecting type with proximal narrowing and partial thromboses and 42 were saccular type. Most of the aneurysms were large (largest diameter $\geq 10 \mathrm{~mm}$ ), and there were 15 small aneurysms (largest diameter $<10 \mathrm{~mm}$ ). The mean aneurysm size was $14.4 \pm 9.6 \mathrm{~mm}$. Two patients had bilateral OSAs.

The types of coils used varied by operator and changed over the period of the study. The types of coils varied; bare platinum coils and Hydrocoils from Microvention, Cordis, and M.T.I-ev3 were used in the treatment of 44 aneurysms. In the recent 7 patients, Chinese-manufactured coils (Jasper, Shanghai, China) were used in conjunction with other coils.

Of the 44 aneurysms, 26 (59.1\%) were treated with stent assistance, $9(20.5 \%)$ were treated without the assistance of adjunctive techniques, 7 (15.9\%) were treated with parent vessel occlusion for their giant size, and 2 (4.5\%) were treated with balloon assistance. Results from immediate post-embolization angiography demonstrated that 41 (93.2\%) aneurysms had complete or nearly complete occlusion, and 3 $(6.8 \%)$ aneurysms had incomplete occlusion.

Of those aneurysms with incomplete occlusion, all were unruptured aneurysms. Forty patients (95.2\%) had a followup angiogram, the average time between initial treatment and follow-up was 7.6 months (range from 3 to 18 months). The follow-up modality was DSA. Among those cases, 35 (79.5\%) aneurysms were completely, 4 (9.1\%) were near completely, and 5 (11.4\%) were incompletely occluded on angiographic follow-ups. Three aneurysms, which were incompletely occluded, showed stable occlusion on the follow-up angiogram, and there was minor recanalization in 2 aneurysms, of which one was re-treated completely.

Among unruptured aneurysms, 2 ischemic complications occurred in 2 cases where a stent was used. There were no evidence of thromboembolism on post-embolization 
angiogram and computed tomography (CT) scanning. There were no cases of intraprocedural rupture/perforation. Of the 2 procedural complications, one was weakness of the right arm, which completely recovered, and one was aphasia and hemiparesis that resulted in persistent hemiparesis.

The permanent complication related to treatment occurred 24 hours after embolization when one patient became suddenly hemiparetic and aphasic. It was associated with a nonocclusive clot and distal emboli. She made a good recovery but still has a residual paresis of the right hand. There was one death $(2.4 \%)$ in our series, which resulted from major embolic infarcts of middle cerebral artery. The major embolic event occurred in a 20-year old man who presented with a larger partially thrombosed dissecting aneurysm on post-coiling 6 days. Mean length of follow-up for our patients was 14.2 months (range, 1 to 44 months). A favorable outcome (GOS score of 4 or 5) was achieved in $41(97.6 \%)$ patients at the time of follow-up. During the follow-up period, there was no episode of hemorrhage and no death. The OSA-associated visual disorders completely recovered in $64.3 \%$ (9 of 14) patients. Complete and subtotal occlusion was observed in $37(95 \%)$ patients and recanalization in 2 patients (5\%) at 6 and 18 months, one was re-treated.

Neither age $(p=0.815)$ nor aneurysmal size $(p=0.256)$ had any significant association with rupture. Perioperative complications $(p=1.000)$, post-procedural angiographic results $(p=0.579)$, clinical $(p=0.309)$ and angiographic outcomes $(p=1.000)$ were also not statistically significantly different between ruptured and unruptured aneurysms (Table II).

Table I: Aneurysm Characteristics in Consecutive Case Series

\begin{tabular}{lcc}
\hline & Ruptured & Unruptured \\
\hline Patient number & 7 & 35 \\
\hline $\begin{array}{l}\text { Patient age (mean } \pm \text { SD, } \\
\text { years) }\end{array}$ & $52 \pm 19.1$ & $50.6 \pm 13.4$ \\
\hline Male & 3 & 9 \\
\hline Female & 4 & 26 \\
\hline Mean size $(\mathbf{m m})$ & $10.6 \pm 7.8$ & $15.1 \pm 9.8$ \\
\hline Saccular type & 6 & 34 \\
\hline
\end{tabular}

\section{DISCUSSION}

In this article, we have presented a single-center series focused on the safety, procedural techniques, and short- and long term occlusion rates for coil embolization of OSAs. Our results have demonstrated high rates of complete or nearly complete occlusion immediately and at the follow-up period.

Many papers have been published on surgery for paraclinoid (OSA) aneurysms $(2,3,6,16-18,20,22,23,27)$. They reported a wide range of mortality rates from 0 to $13.8 \%$ and morbidity rates up to $26.8 \%$ (Table III). The complication rates associated with surgical treatment are $0 \%-25 \%$ and the complete obliteration rates of aneurysms are $66.7 \%-100 \%$. The mean age in these studies is $42-50$ years, with SAH rate of $0-80.8 \%$, mostly large and giant but with some small aneurysms (Table IV), which are comparable to those in our study (13).

Despite the advantages and improvement in surgical techniques, significant morbidity and mortality was associated with surgical treatment of these aneurysms (13). Our group of OSAs, which included small, large and giant aneurysms, had a procedure-related morbidity of $4.5 \%$, permanent major morbidity of $2.4 \%$ and mortality of $2.4 \%$. This compares favorably with the previously reported surgical series.

Advances in adjunctive techniques, such as stent or balloonassisted coiling, have made the endovascular occlusion of intracranial aneurysms easy and safe $(11,13)$. However, a few series of OSA, which were treated with endovascular coiling, were reported (13) (Table III). Hauck et al. (8) reported a complete obliteration rate of $26.7 \%$ without any complication and death. Heran et al.(9) published a mortality rate of $11.8 \%$ in their series. Roy et al.(21) published 28 cases of OSAs with 3 deaths (10.7\%), one permanent morbidity (3.6\%) and $50 \%$ complete obliteration rate. In the other 2 papers $(14,24)$, the reported complete obliteration rates of OSAs were as high as $87.3 \%$ and $88.9 \%$ with a complication rate of $18.3 \%$ and $0 \%$. In our series, the favorable clinical outcome rate was $97.6 \%$ and complete to near-complete occlusion rate was $88.6 \%$.

The indication for treatment of unruptured intracranial aneurysms is controversial. OSAs include a subset with a relatively low rupture rate (15). For unruptured carotid cave and small OSAs, decision-making regarding whether or not to treat the aneurysm may be the most difficult step (7). Therefore, when deciding for the treatment of unruptured OSAs, the risk of the treatment procedure should be balanced against the benign

Table II: Procedure-Related Complications, Angiographic and Clinical Outcomes

\begin{tabular}{lccc}
\hline & Ruptured & Unruptured & p value \\
\hline Perioperative complications & 1 & 2 & 1.000 \\
\hline Complete occlusion after embolization & 5 & 30 & 0.579 \\
\hline Complete occlusion at follow-up & 6 & 29 & 1.000 \\
\hline Good recovery at follow-up & 6 & 34 & 0.309 \\
\hline Total & 7 & 35 & - \\
\hline
\end{tabular}




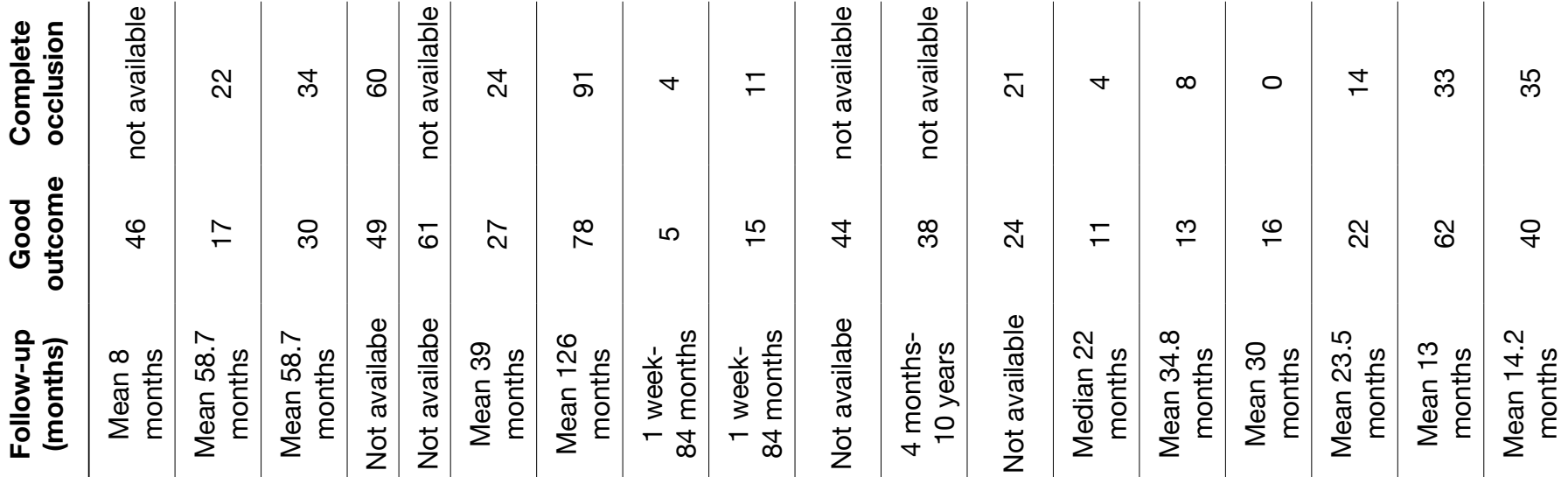

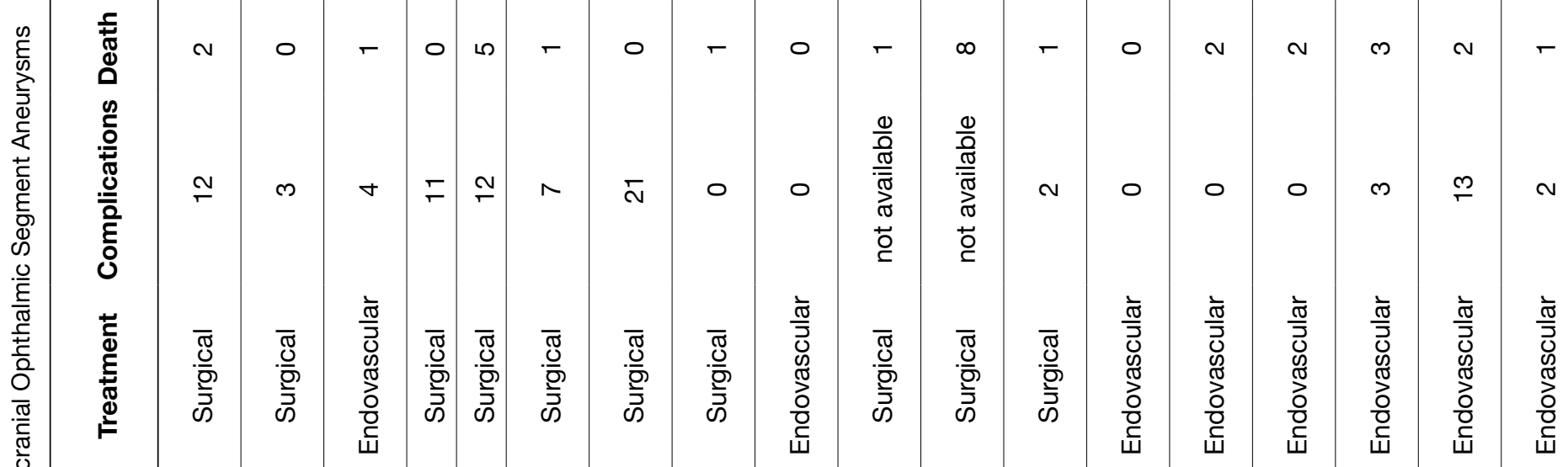

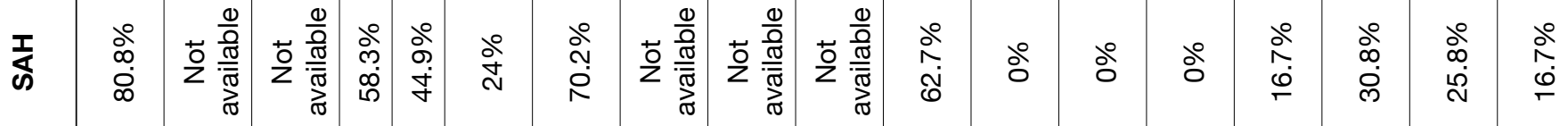

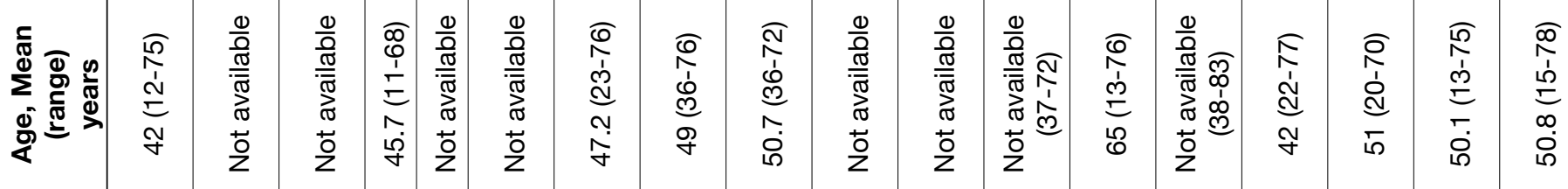

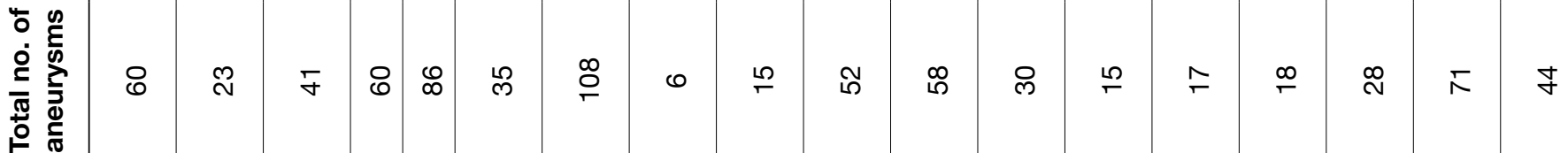

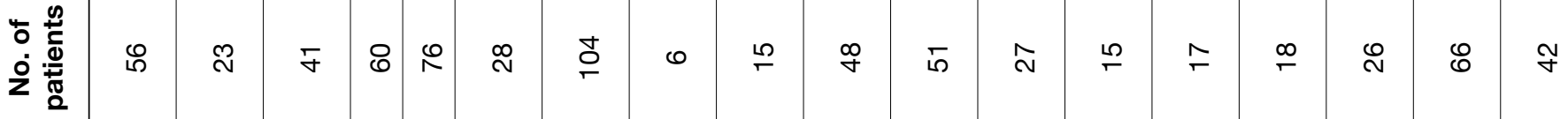

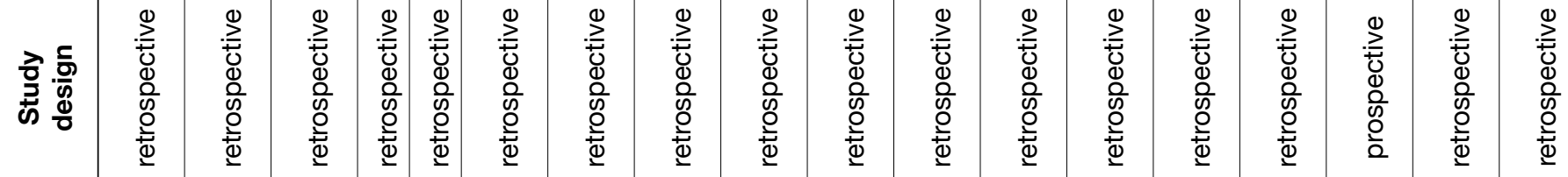

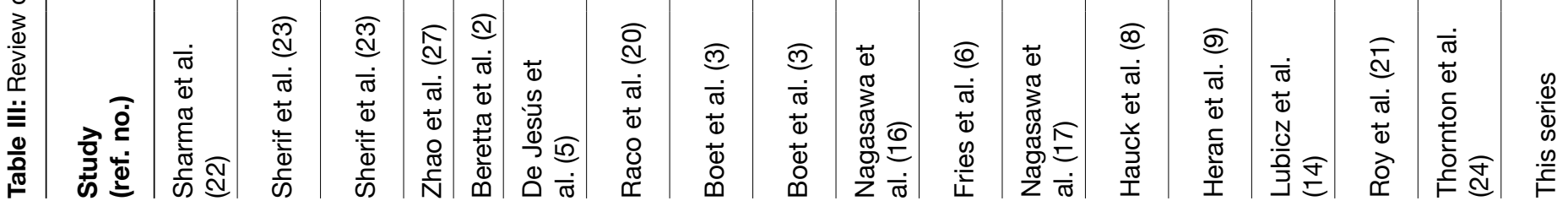


Table IV: Indications for Surgical and Endovascular Treatment according to the Studies in the Literature

\begin{tabular}{ll}
\hline Study & Indications \\
\hline & $\begin{array}{l}\text { Indications for microsurgery: superior aneurysm projection, giant/large or wide necked aneurysms } \\
\text { and aneurysms at branching sites. } \\
\text { Indications for embolization: narrow necks, neck calcification, close aneurysm relation to the clinoid } \\
\text { process or adhesion to the distal dural ring, and aneurysm location in the concavity of the carotid } \\
\text { siphon curve. }\end{array}$ \\
\hline & $\begin{array}{l}\text { Microsurgery would be more advantageous for cases where the neck is broad and where the } \\
\text { topography concerning aneurysmal multiplicity or the branching site of the ophthalmic artery is not } \\
\text { fully understood by preoperative imaging. }\end{array}$ \\
\hline
\end{tabular}

natural history of the OSA (4). Our experience has shown that the risk of treating unruptured intracranial OSA is as low as $2.4 \%$.

Delayed aneurysm ruptures have been previously reported but the mechanisms are still unclear. Flow diverter stents are devices designed to treat complex aneurysms. Today, some randomized clinical studies and registries are in progress and will contribute to our current knowledge especially on the place of flow diverters in the treatment of intracranial aneurysms (25).

This study has various limitations. Most of the series in the literature were single-center and retrospective studies. In addition, possible publication bias may be present in these series because series with positive results were mostly published (4). Meanwhile, our study showed that endovascular treatment of intracranial OSAs can be performed with an acceptable risk.

\section{CONCLUSION}

We treated OSAs with endovascular techniques in 42 patients. We have demonstrated complete or near complete occlusion in $93.2 \%$ at initial treatment, with a mortality of $2.4 \%$ and a morbidity of $2.4 \%$. Endovascular embolization is a safe and effective treatment modality in cases of OSAs.

\section{- REFERENCES}

1. Barami K, Hernandez VS, Diaz FG, Guthikonda M: Paraclinoid carotid aneurysms: Surgical management, complications, and outcome based on a new classification scheme. Skull Base 13(1):31-41, 2003

2. Beretta F, Andaluz N, Zuccarello M: Aneurysms of the ophthalmic (C6) segment of the internal carotid artery: Treatment options and strategies based on a clinical series. J Neurosurg Sci 48(4):149156, 2004

3. Boet R, Wong GK, Poon WS, Lam JM, Yu SC: Aneurysm recurrence after treatment of paraclinoid/ophthalmic segment aneurysms--a treatment-modality assessment. Acta Neurochir (Wien) 147(6):611-616, 2005

4. Brinjikji W, Lanzino G, Cloft HJ, Rabinstein A, Kallmes DF: Endovascular treatment of very small ( $3 \mathrm{~mm}$ or smaller) intracranial aneurysms: report of a consecutive series and a meta-analysis. Stroke 41(1):116-121, 2010
5. De Jesús O, Sekhar LN, Riedel CJ: Clinoid and paraclinoid aneurysms: Surgical anatomy, operative techniques, and outcome. Surg Neurol 51(5):477-488, 1999

6. Fries G, Perneczky A, van Lindert E, Bahadori-Mortasawi F: Contralateral and ipsilateral microsurgical approaches to carotidophthalmic aneurysms. Neurosurgery 41(2):333-343,1997

7. Giannotta SL: Ophthalmic segment aneurysm surgery. Neurosurgery 50(3):558-562, 2002

8. Hauck EF, Welch BG, White JA, Replogle RE, Purdy PD, Pride LG, Samson D: Stent/coil treatment of very large and giant unruptured ophthalmic and cavernous aneurysms. Surg Neurol 71(1):19-24, 2009

9. Heran NS, Song JK, Kupersmith MJ, Niimi Y, Namba K, Langer DJ, Berenstein A: Large ophthalmic segment aneurysms with anterior optic pathway compression: assessment of anatomical and visual outcomes after endosaccular coil therapy. J Neurosurg 106(6):968-975, 2007

10. Jennett $B$, Bond $M$ : Assessment of outcome after severe brain damage: A practical scale. Lancet 1:480-484,1975

11. Kang HS, Han MH, Kwon BJ, Kwon OK, Kim SH, Choi SH, Chang $\mathrm{KH}$ : Short-term outcome of intracranial aneurysms treated with polyglycolic acid/lactide copolymer-coated coils compared to historical controls treated with bare platinum coils: A single center experience. AJNR Am J Neuroradiol 26: 1921-1928,2005

12. Kang HS, Kwon BJ, Kwon OK, Jung C, Kim JE, Oh CW, Han $\mathrm{MH}$ : Endovascular coil embolization of anterior choroidal artery aneurysms. J Neurosurg 111(5):963-969, 2009

13. Liang G, Li Z, Gao X, Zhang H, Lin J, Feng S, Wei X: Using Onyx in endovascular embolization of internal carotid artery large or giant aneurysms. Eur J Radiol 81(8):1858-1862, 2012

14. Lubicz B, Gauvrit JY, Leclerc X, Lejeune JP, Pruvo JP: Giant aneurysms of the internal carotid artery: Endovascular treatment and long-term follow-up. Neuroradiology 45(9):650- 655, 2003

15. Lv X, Li Y, Wu Z: Endovascular management for bilateral ophthalmic segment "kissing aneurysms" presenting with nasal bleeding: case report. Neuroradiol J 21:266-269, 2008

16. Nagasawa S, Kawabata S, Deguchi J, Kuroiwa T, Ohta T, Tsuda E: Microsurgical results of paraclinoid aneurysms of the internal carotid artery: Microsurgery versus intravascular surgery. No Shinkei Geka 27(9):809-816, 1999

17. Nagasawa $\mathrm{S}$, Ohta $\mathrm{T}$, Tsuda $\mathrm{E}$ : Surgical results and the related topographic anatomy in paraclinoid internal carotid artery aneurysms. Neurol Res 18(5):401-408, 1996

18. Ohnishi H, Kosimae $\mathrm{N}$ : Surgical management of cerebral aneurysms in comparison with endovascular treatment. Interv Neuroradiol 4 Suppl 1:149-152, 1998 
19. Qureshi Al, Vazquez G, Tariq N, Suri MF, Lakshminarayan K, Lanzino G: Impact of international subarachnoid aneurysm trial results on treatment of ruptured intracranial aneurysms in the United States. J Neurosurg 114(3):834-841, 2011

20. Raco A, Frati A, Santoro A, Vangelista T, Salvati M, Delfini R, Cantore G: Long-term surgical results with aneurysms involving the ophthalmic segment of the carotid artery. J Neurosurg 108(6):1200-1210, 2008

21. Roy D, Raymond J, Bouthillier A, Bojanowski MW, Moumdjian $R$, L'Espérance G: Endovascular treatment of ophthalmic segment aneurysms with Guglielmi detachable coils. AJNR Am J Neuroradiol 18(7):1207-1215, 1997

22. Sharma BS, Kasliwal MK, Suri A, Sarat Chandra P, Gupta A, Mehta VS: Outcome following surgery for ophthalmic segment aneurysms. J Clin Neurosci 17(1):38-42,2010
23. Sherif C, Gruber A, Dorfer C, Bavinzski G, Standhardt H, Knosp E: Ruptured carotid artery aneurysms of the ophthalmic (C6) segment: Clinical and angiographic long term follow-up of a multidisciplinary management strategy. J Neurol Neurosurg Psychiatry 80(11):1261- 1267, 2009

24. Thornton J, Aletich VA, Debrun GM, Alazzaz A, Misra M, Charbel $\mathrm{F}$, Ausman JI: Endovascular treatment of paraclinoid aneurysms. Surg Neurol 54: 288 -299, 2000

25. van Rooij W.J, Sluzewski M, van der Laak C: Flow diverters for unruptured internal carotid artery aneurysms: Dangerous and not yet an alternative for conventional endovascular techniques. AJNR Am J Neuroradiol 34:3-4, 2013

26. Wu Z, Lv X, Li Y, Jiang C, Yang X: Endovascular treatment for complex intracranial aneurysms: Lessons learnt in five patients. Neuroradiol J 23: 459-466, 2010

27. Zhao J, Wang S, Zhao Y, Sui D, Zhang Y, Tang J, Lui W: Microneurosurgical management of carotid-ophthalmic aneurysms. J Clin Neurosci 13(3):330-333, 2006 